\title{
Dynamic Magnetic Properties of the Magnetostrictive Rapidly-Quenched Alloys
}

\author{
R. Kolano, A. Kolano-Burian, J. Szynowski, M. Polak, \\ M. SteCZKOWSKA-KeMPKA
}

Institute of Non-Ferrous Metals, Sowińskiego 5, 44-100 Gliwice, Poland

This work was aimed at investigating the FeNbCuSiB and FeNiMoB type alloys exhibiting relatively high saturation magnetostriction after suitable heat treatment, which makes them suitable for application in force sensors. Samples of both alloys were prepared in a form of toroidal cores wound from amorphous ribbons obtained by melt-spinning, and then the cores were annealed under longitudinal and transverse magnetic field. An effect of the induced magnetic anisotropy and of the applied compressive stresses on the dynamic magnetic properties of both alloys within a frequency range from $50 \mathrm{~Hz}$ to $50 \mathrm{kHz}$ was studied.

PACS numbers: 75.30.Gw, 75.60.Ej, 75.80.+q

\section{Introduction}

The possibility of application of rapidly-quenched soft magnetic materials in the force sensors was studied by some authors (e.g. [1, 2]), but there are no comprehensive literature reports on the use of rapidly-quenched materials exhibiting high saturation magnetostriction $\lambda_{\mathrm{s}}>25 \times 10^{-6}$ and low coercivity $H_{\mathrm{c}}(2-5 \mathrm{~A} / \mathrm{m})$ for these purposes, although these materials are potentially very suitable for this type of applications. The examples of such materials are the $\mathrm{Fe}_{40} \mathrm{Ni}_{38} \mathrm{Mo}_{4} \mathrm{~B}_{18}$ and $\mathrm{Fe}_{73.5} \mathrm{Cu}_{1} \mathrm{Nb}_{3} \mathrm{Si}_{13.5} \mathrm{~B}_{9}$ alloys [3, 4], which have been studied under this work. Therefore, the aim of this work was to carry out comprehensive research into fabrication conditions of the cores from these alloys, characterised by an amorphous structure and exhibiting magnetostriction over $25 \times 10^{-6}$ and the induced transverse and longitudinal magnetic anisotropies. Moreover, the changes in their dynamic magnetic properties in dependence on the applied compressive stress and on magnetising field frequency were investigated.

\section{Experimental}

The ribbons from the $\mathrm{Fe}_{40} \mathrm{Ni}_{38} \mathrm{Mo}_{4} \mathrm{~B}_{18}$ and $\mathrm{Fe}_{73.5} \mathrm{Cu}_{1} \mathrm{Nb}_{3} \mathrm{Si}_{13.5} \mathrm{~B}_{9}$ alloys were fabricated by melt-spinning technique [5] using the casting parameters from Table I. 
TABLE I

The casting parameters

\begin{tabular}{c|c|c|c|c}
\hline \hline Alloy type & $\begin{array}{c}\text { Wheel speed } \\
{[\mathrm{m} / \mathrm{s}]}\end{array}$ & $\begin{array}{c}\text { Crucible-wheel } \\
\text { distance }[\mathrm{mm}]\end{array}$ & $\begin{array}{c}\text { Charge } \\
\text { temp. }[\mathrm{K}]\end{array}$ & $\begin{array}{c}\text { Ejecting } \\
\text { pressure }[\mathrm{kPa}]\end{array}$ \\
\hline FeNiMoB & 36 & 0.4 & 1553 & 20 \\
FeCuNbSiB & 36 & 0.3 & 1573 & 19
\end{tabular}

TABLE II

Parameters of thermo-magnetic treatment

\begin{tabular}{c|c|c|c}
\hline \hline Alloy type & $\begin{array}{c}\text { Temperature } \\
T_{\mathrm{a}}[\mathrm{K}]\end{array}$ & $\begin{array}{c}\text { Time } \\
{[\mathrm{min}]}\end{array}$ & $\begin{array}{c}\text { External field }[\mathrm{kA} / \mathrm{m}] \\
H_{\mathrm{L}} / H_{\mathrm{t}}\end{array}$ \\
\hline FeNiMoB & 658 & 60 & $2 / 150$ \\
FeCuNbSiB & 738 & 60 & $2 / 150$
\end{tabular}

The obtained ribbons were 22 and $21 \mu \mathrm{m}$ in thickness, respectively, their width was $24.5 \mathrm{~mm}$, and their amorphousness in the as-quenched state was checked by the X-ray diffraction method (XRD). A series of toroidal cores were wound from these ribbons, $32 \mathrm{~mm}$ and $26 \mathrm{~mm}$ in the external and internal diameters, respectively, and $24.5 \mathrm{~mm}$ high. In order to form their anisotropic magnetic properties the cores were subjected to annealing at pre- determined temperatures under argon atmosphere, in a presence of longitudinal magnetic field $H_{\mathrm{L}}$ (the field lines arranged in parallel to the casting direction) or under transverse magnetic field $H_{\mathrm{t}}$ (i.e. perpendicular to the casting direction). The parameters of treatment are given in Table II.

The XRD examination performed after the treatment showed that the cores had an amorphous structure, and their magnetostriction $\lambda_{\mathrm{s}}$ was equal to $27 \times 10^{-6}$ and $26 \times 10^{-6}$, respectively. Next, in order to determine an effect of compressive forces on the dynamic magnetic properties of the cores, the samples were placed in a special ceramic boxes, the top cover of which was subjected to a uniform compressive stress, and the measurements of their magnetic properties at the selected frequencies were performed using computer-controlled measuring system Remacomp C-100.

\section{Results and discussion}

Figures 1a and b illustrate dependence of coercivity $H_{\mathrm{c}}$ and magnetic permeability $\mu$ on a uniform compressive stress $\sigma$ applied perpendicularly to the core base. The $H_{\mathrm{c}}(\sigma)$ and $\mu(\sigma)$ dependences are shown in these figures for the cores from the FeNiMoB and FeCuNbSiB alloys with the induced transverse $\left(H_{\mathrm{t}}\right)$ and longitudinal $\left(H_{1}\right)$ magnetic anisotropies. 


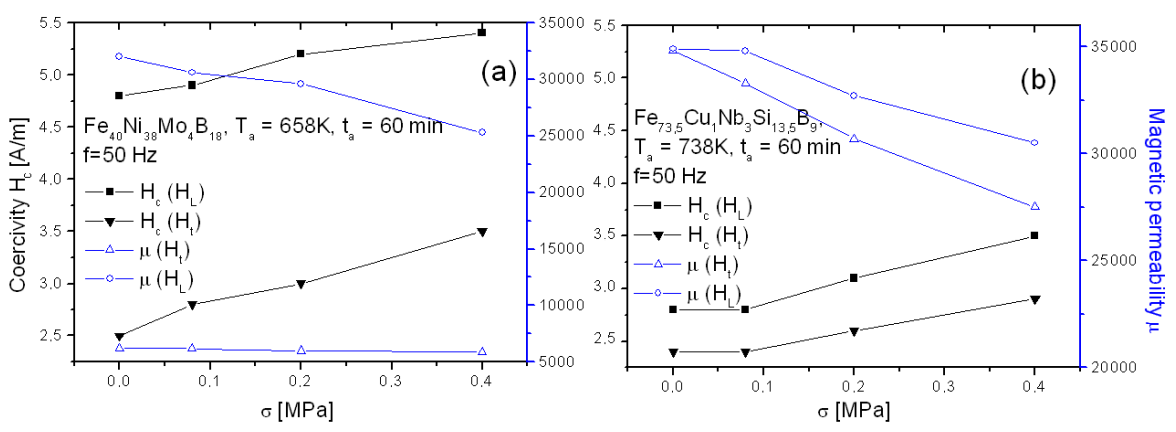

Fig. 1. An effect of compressive stress $\sigma$ on $H_{\mathrm{c}}$ and $\mu$ for the FeNiMoB (a) and $\mathrm{FeCuNbSiB}$ (b) alloys with the induced transverse and longitudinal anisotropies.
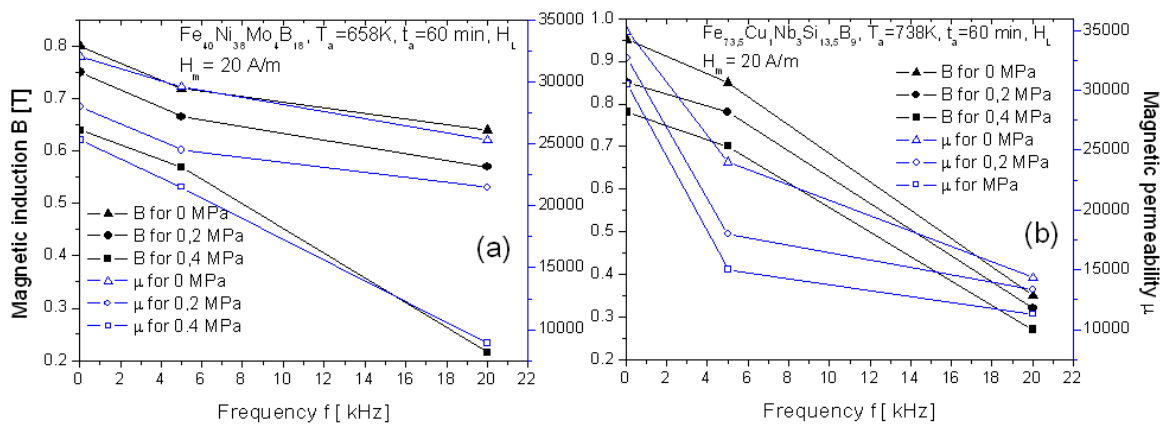

Fig. 2. Dependence of $B$ and $\mu$ on magnetising field frequency $f$ for the FeNiMoB (a) and $\mathrm{FeCuNbSiB}$ (b) alloys with the induced longitudinal magnetic anisotropy.

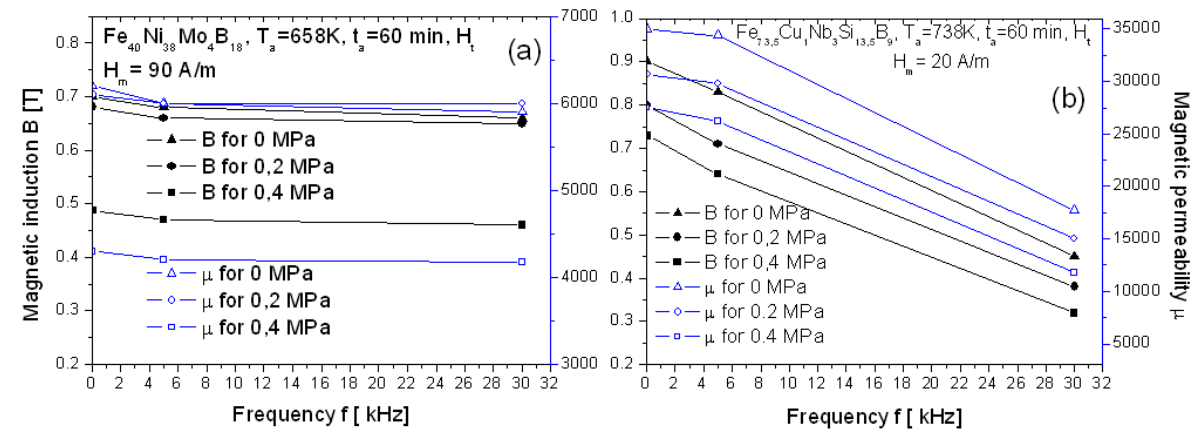

Fig. 3. Dependence of $B$ and $\mu$ on magnetising field frequency $f$ for the FeNiMoB (a) and $\mathrm{FeCuNbSiB}$ (b) alloys with the induced transverse magnetic anisotropy.

It is seen in Fig. 1a that an increase in compressive stress $\sigma$ from 0 to 0.4 $\mathrm{MPa}$ in the cores with longitudinal anisotropy results in $H_{\mathrm{c}}$ increase by about 1 $\mathrm{A} / \mathrm{m}$ and in $\mu$ decrease by about 6000 . Similar changes in $\sigma$ in the core with a transverse magnetic anisotropy resulted in the $H_{\mathrm{c}}$ increase also by about $1 \mathrm{~A} / \mathrm{m}$, 
whereas $\mu$ remained almost unchanged. This considerable difference between $\mu$ in the cores with longitudinal and transverse magnetic anisotropies results from significant differences in magnetic remanence $B_{\mathrm{r}}$ for both types of cores.

Figures 2 and 3 show dependence of the magnetic induction $B$ and magnetic permeability $\mu$ on a magnetising field frequency for the FeNiMoB and FeCuNbSiB cores with the induced longitudinal and transverse magnetic anisotropies. The dependences determined for all grades of cores are of a similar character, except for the FeNiMoB core with a transverse magnetic anisotropy, for which the $B(f)$ and $\mu(f)$ relationships are constant over $5 \mathrm{kHz}$.

\section{Conclusions}

The dynamic magnetic properties $B(f), H_{\mathrm{c}}(f)$ and $\mu(f)$ determined within a frequency range from $50 \mathrm{~Hz}$ to $50 \mathrm{kHz}$ for the cores made from the $\mathrm{Fe}_{40} \mathrm{Ni}_{38} \mathrm{Mo}_{4} \mathrm{~B}_{18}$ and $\mathrm{Fe}_{73.5} \mathrm{Cu}_{1} \mathrm{Nb}_{3} \mathrm{Si}_{13.5} \mathrm{~B}_{9}$ alloys with the induced longitudinal and transverse magnetic anisotropies have confirmed that these cores are suitable for application in force sensors. Moreover, the results obtained indicate that for the measurements of compressive stresses below 0.3 MPa it is more advantageous to use the cores with longitudinal anisotropy, whereas the cores with a transverse magnetic anisotropy are more suitable for application at the compressive stresses over $0.3 \mathrm{MPa}$. a

\section{Acknowledgments}

This work was financed by the Polish Ministry of Education and Science under the Targeted Research Project performed over the years 2005-2008.

\section{References}

[1] A. Bienkowski, R. Szewczyk, R. Kolano, Phys. Status Solidi A 189, 821 (2002).

[2] A. Bienkowski, R. Kolano, R. Szewczyk, J. Magn. Magn. Mater. 254-255, 67 (2003).

[3] R.N.G. Dalpadado, K. Shirae, J. Appl. Phys. 52, 1920 (1981).

[4] T. Kulik, A. Hernando, J. Magn. Magn, Mater. 133, 310 (1994).

[5] R. Kolano, A. Kolano-Burian, J. Szynowski, N. Wojcik, M. Polak, Rudy Metale R51, 128 (2003) (in English). 